\title{
Environmental security and sustainable development of large urban centres
}

\author{
Ekaterina Polyakova ${ }^{1 *}$, Larisa Gorina ${ }^{1}$ \\ ${ }^{1}$ Institute of Engineering and Environmental Security, Togliatti State University, Belorusskaya str. 14, \\ 445020 Togliatti, Russian Federation
}

\begin{abstract}
Our article focuses on the environmental security and sustainable development of large urban centres. In addition, it analyses the demographic and ecological situation in the Russian Federation in order to determine the environmental influence of the social and economic factors as well as the factors of development and growth of large urban hubs. The results demonstrate that there exists a necessity to increase the environmental security in order to foster the sustainable development in the regions and urban centres that would lead to the better satisfaction with the level of life, lower mortality, and growing economic well-being. All of these can be achieved using balanced state support and policies targeted at increasing environmental security and creation of the sustainable future for the generation to come.
\end{abstract}

\section{Introduction}

The report entitled "Common Future" was published by the World Commission on Environment and Development (WCED) (also known as the Brundtland Commission) back in 1987, over 30 years ago but it already contained a term "environmental security" [1,2]. Now, more than three decades later, this term is still an important issue that many countries and governments struggle to comprehend and to effectively implement.

The rise of sustainable development has refocused development approaches, and many experts see it as a multi-faceted approach to reconciling socio-political concerns with human development issues [3,4]. Although sustainable development has become a globally recognized term for responsible growth, its significance and measurement remain diverse and often complex, even as it becomes a global standard. The World Bank combined the concept of environmental security with the concepts of generational justice and equality between generations, arguing for the importance of "environmental security" as an integral part of sustainable development as a whole [5, 6]. Growing environmental awareness in developing countries has led to environmental problems being seen as important enough to be considered a safety problem.

The progress in these issues was long and it is still ongoing. In the 1960s, NGOs, including the Environmental Defence Fund (EDF) and the International Union for Nature Conservation (IUCN), began working on environmental security. In the 1970s, nuclear power

\footnotetext{
*Corresponding author: polyakova-88@mail.ru
} 
and the associated proliferation and development of newforms of energy occurred [7]. It is essential that measures are taken to protect ecosystems, land and water, to combat global warming and to combat climate change, including the use of renewable energy sources such as wind and solar energy. One would probably agree that nature is in crisis, threatened by climate change, human activities, pollution, deforestation, land degradation and humananimal conflicts. These include biodiversity, water, air, soil and soil quality, biodiversity and species protection. These pieces are part of the puzzle of a sustainable society because they are the basic ingredients of everyday life and are important for human health and well-being. Nevertheless, many of the current national policies aim to ensure economic growth without a specific sustainable development strategy.

In general terms, sustainable development is a concept that is intended to combine economic, social, environmental and social development and environmental security. It offers the opportunity to find ways to achieve development that is economically, socially and environmentally sustainable [8]. In order to address environmental concerns, one needs to reflect on the role of the environment in the development of a sustainable society and its impact on human health, well-being and livelihoods. In this context, we consider it important to raise awareness of the need for national governments to implement a sustainable development strategy with a focus on environmental safety and protection. This is especially relevant in the case of large urban hubs such as cities and towns.

While national policies deny the threat of climate change, the emergence of various movements has underscored the urgent need to involve civil society and reverse the current situation, especially in the context of a global climate crisis. Moreover, at the time of the COVID-19 pandemic, awareness of the importance of environmental safety and protection in the concept of sustainable development, especially in the context of climate change, was lacking [9]. This is a very good example why the environmental awareness needs to be fostered and promoted.

When the well-being of the environment - the existence and existence of people around the world - is crucial, it becomes an international security issue. The environment is in under threat from the human activity and must be protected and safeguarded the people's combined efforts. It can therefore be seen in two ways: firstly, as an environmental concept of safety and, secondly, as part of the security of human life. Rising emissions of greenhouse gases such as carbon dioxide and methane are damaging human well-being - being and survival and provoking violent conflicts that are seen as a threat to the security of human life and the survival of the planet. In the 1990s, the focus was on phasing out the use of ozone-depleting substances and transboundary contamination problems ranging from air pollution to waste water. The national security community considered environmental security to be a matter related to pollution from former Soviet military activities and the threat to human and economic health from improperly maintained nuclear weapons and industrial pollution. But, as sustainability and resource conservation have become more important than ever to the governments all around the world in the last decade, environmental security has taken on a new meaning [10].

This article tackles the environmental security and sustainable development of large urban centres using some examples from Russia. Our results might be useful for the city planners as well as policymakers and stakeholders dealing with sustainable development and urban planning.

\section{Ecological situation and demographic changes}

Overall, it can be noticed that people in developing countries tend to feel the effects of environmental problems more strongly because they live in coastal regions directly affected by climate change and the associated extreme weather events. On the other hand, people 
residing in developed and industrialized countries tend to contribute a great deal to the environmental pollution and degradation. The United States, for example, which accounts for $5 \%$ of the world's population, currently produces more greenhouse gas emissions than any other country in the world [11]. As local resources, including plants and animals, are depleted, the most vulnerable populations are the ones feeling the effects most. They also have less access to clean water, increased pollution and higher rates of disease and mortality, all of which can lead to reduced biodiversity. Change in the size analyses show that population growth is declining, deforestation is accelerating, accompanied by afforestation, and a range of different responses from humans and the environment are taken into account. Although these interconnected problems seem overwhelming, it is important to remember that people can make changes that positively affect the planet. One example is Latin America, where many nations are experiencing declining rural populations and persistent deforestation. A dramatic example is Ecuador, whose Amazon forest canopies are rapidly depleted by the growth of settlements and frontier farmers, while the rural population is declining due to declining fertility and rapid urbanization [12]. This apparent anomaly is explained by a small population, which is a minority of the country's urban population, has moved to the forest border and contributes disproportionately to its total deforestation. Although the analysis of occurrences refers to population density, it is striking that the majority of the studies examined focus on human-population dynamics, but this is not represented in the data. There are some incidents that are related to the growth rate of the human population, which is the second most important factor covered in this study, followed by socio-economic aspects. Several studies have highlighted the importance of population density as a key factor for forest health and biodiversity loss. However, only a small number of incidents have been investigated to investigate the impact of human-population dynamics on forest health and biodiversity loss [13].

The population of world's cities has doubled in 10 years and the rural population has doubled due to high fertility and migration, but the population of cities has disproportionally increased over these same years. Other factors include the expansion of protected areas, the creation of new protected areas and the reduction in summer outflows due to global warming. As farmers increasingly move into areas previously considered too marginal for agriculture, and pastoralists are under pressure from pasture restrictions in these areas (partly due to newly established protected areas), there are major conflicts between farmers and pastoralists in the region. This pressure on the country has led to a strain on water and other resources, which has led to a large migration into the basin. One of the challenges for research in this area is the common ownership of water resources. This challenge is caused by the fact that water resources, which are becoming scarcer, have been altered in the institutional context. The field could use further studies of catchment areas and watersheds to understand how variables such as population and climate change could influence the necessary institutional responses. It would also help to better understand and resolve competition between urban and rural water consumption as the world urbanizes. This represents a major challenge for research in the field of water resource management and conservation. Today, more than $50 \%$ of the world's population is urban, and $85 \%$ has some anthropogenic influence. Urban areas occupy more land than agriculture today, and the world's population now displaces $50-80 \%$ of urban areas [14]. We can conclude from this that large-scale land conversion is largely a rural phenomenon and can be attributed to a swelling urban middle class. Simple models like this look for driving factors, but if something cannot be captured by the model, it is the sudden change in the driving factor that causes it, not the anthropogenic factors.

Therefore, the model cannot predict the long-term effects of climate change on land use and land use in the future. Nevertheless, the ecologically motivated theory of demographic change in the context of climate change highlights key driving factors and provides insights into the possible mechanisms behind demographic change [15]. These factors have different 
effects and appear to affect changing populations in more than one area than in any other. This phenomenon can be well explained by the theory of pole evolution, but there could also be impacts that depend on other factors, such as changes in land use, climate change, or resource availability. These impacts also depend on the spatial conditions of the area; for example, urban population changes are more limited by existing land use policies than rural ones.

\section{Environmental security in urban centres}

As the climate change is growing, concern about water and food security is growing as urban populations is increasing. In order for cities to be liable and sustainable in the future, a natural resource base and ecosystem services for the urban area around the city must be preserved [16]. The development of a peri-urban area involves a changing mix of land use, housing, infrastructure and land use. Over time, the infrastructure supporting the construction infrastructure (e.g. roads, bridges, water and sanitation systems) will have to adapt to the needs of the urban environment. The growing importance of cities means that they are now the only ones that can address the problems of a growing population while reducing carbon emissions [17]. Urbanization means the loss of natural space and the need for new housing, as well as the development of new buildings and infrastructure. Most of the world's population now lives in urban centres, and these are facing their own problems and challenges. This is exactly what master students of urban studies could be looking for in order to better prepare for the future. The study of the urban centre as a network can help us to understand social development, as each city cares about the environment around it.

As cities become more prosperous, investments in infrastructure and services tend to reduce the large risks. However, disaster risks are increasing in fast-growing small and medium-sized urban centres, as well as in rural areas and larger cities. By 2050, more than two-thirds of the world's population will live in urban areas. Urban development is driving a new pattern of large and intense risk: most urban growth is taking place in major urban centres such as Moscow, New York City, London, Paris, Beijing, or Tokyo [18]. It is therefore time to start today to ensure that urban areas will be inclusive, safe, sustainable and resilient. Table 1 that follows show the dynamics of urban population growth in the largest cities of Russia.

Table 1. Population growth in the largest Russian cities (2020)

\begin{tabular}{|c|c|c|c|}
\hline No. & City & Population & $\begin{array}{c}\text { Growth relative } \\
\text { to 2010 census }\end{array}$ \\
\hline 1 & Moscow & 12678 & $10,2 \%$ \\
\hline 2 & Saint Petersburg & 5398 & $10,6 \%$ \\
\hline 3 & Novosibirsk & 1625 & $10,2 \%$ \\
\hline 4 & Yekaterinburg & 1493 & $10,5 \%$ \\
\hline 5 & Kazan & 1257 & $9,8 \%$ \\
\hline 6 & Nizhny Novgorod & 1252 & $-0,01 \%$ \\
\hline 7 & Chelyabinsk & 1196 & $5,8 \%$ \\
\hline 8 & Samara & 1156 & $-0,77 \%$ \\
\hline 9 & Omsk & 1154 & $-1 \%$ \\
\hline 10 & Rostov-on-Don & 1137 & $4,4 \%$ \\
\hline
\end{tabular}

It is clear that densely built urban areas tend to be associated with risks of their own, such as climate change, air pollution, traffic congestion, land use changes, water and soil pollution, water pollution from wastewater treatment plants and other sources, lack of access to clean air and water, poor air quality, high levels of crime and violence, and high health and safety risks. With cities accounting for more than $80 \%$ of global GDP, urbanization contributes to 
sustainable growth by managing better and higher productivity and enabling innovation and new ideas to emerge [19]. But the speed and scale of urbanization bring challenges, including growing demand for better connected transportation systems and the nearly one billion urban poor living in informal settlements, which is an opportunity. United Nations Environment Programme (UNEP) identified the need for more sustainable and resilient development of the growing population and its urban areas as one of their top priorities. By 2050, more than two-thirds of the world's population is projected to live in urban areas, and conflicts are on the rise, resulting in more than half of all forcibly displaced people living in urban areas, according to the World Health Organization. Urbanization is also attractive to many rural residents, as it creates many opportunities to improve their quality of life, according to the World Health Organization. As urbanisation increases, urban planners and policymakers need to consider how to develop and manage ecological resources to meet the needs of urban populations. If cities are to accept urbanization, they also need to know how quickly they can overcome the negative effects of urbanization in order to survive. However, many elements of urbanization can become burdensome if they are not carefully planned. Understanding the dynamics of urban ecosystem services is a key element in the development of sustainable urban planning and decision-making. The Ecosystem Services (ES) approach provides a framework for assessing the status quo, setting targets, setting benchmarks and prioritising ecological functioning that improves urban sustainability and resilience. An important step in the process of assessing urban ecosystems is the integration of the ecosystem - service concept into urban planning and decision-making. The next section briefly discusses what has been added to sustainability and resilience over the past decade. The link between urbanization and GECs, including climate-related disasters, has increased the need for urban areas to adapt to potential risks. The impact on rural areas has been concentrated, although the damage is more extreme and causes more environmental damage than the impact on urban ecosystems such as floods, droughts and forest fires.

\section{Environmental security in the Russian Federation}

There is a question whether and to what extent domestic acceptance of environmental security is reflected in Russia's international relations. To answer this, we are investigating Russia's stance on environmental and security issues. On the global level, Russia could be seen as a platform to ensure its presence, strengthen business interests, and protect the environment [20]. Russia is a party to and participates in the main multilateral environmental agreements, but prefers to maintain the status quo. For Russia, its statements to the United Nations Security Council suggest that it fears that environmental and security issues could be used against the country [21]. Economic and political sanctions imposed by the West against Russia, including against environmental cooperation and technical assistance, have contributed to the negative views of environmental protection. Dropping oil prices as a result of COVID-19 lockdowns and the cuts in international travel led to the economic losses. National sovereignty also stands in the way of the securitisation of the environment. Moreover, the role of national sovereignty in the development of environmental security in Russia and other countries is not clearly defined. This requires a more integrated approach to the development of environmental security in Russia and other countries.

Although air pollution is an urgent threat to Russia's environmental security, this strategy does not analyse and address this problem. The main environmental problems mentioned above concern air and water pollution, water quality and climate change. To present the contemporary idea of environmental security, a number of peace and environmental scientists have begun to stress the importance of addressing common environmental problems arising from human activities such as pollution, climate change and human rights violations. Human health and the environment are being damaged not only by industrialised areas but also by 
non-industrialised ones. In 1987, the World Commission on Environment and Development published its report which popularized the concept of sustainable development and introduced the term "environmental security". This gave rise to the idea of environmental safety as a key component of international environmental policy. In 1997 and 2002, a series of conferences followed: International Conference on Environmental Security and Sustainable Development in Moscow in 1997 and in Paris in 2002. These issues should draw public attention to environmental issues in order to preserve biodiversity and environmental safety as key priorities of environmental policy. In the meantime, new strategies should aim at ensuring long-term successful and sustainable development. Under this approach, this decree could be seen as a new milestone in Russia's environmental strategy. It aims to stimulate public debate on the importance of environmental safety as a key component of international environmental policy. There must be a well-developed strategy document that sets out a clear political framework for the development and implementation of Russian environmental policy [22].

In the same time, Russia faces demographic issues that should also be considered with regard to its environmental security. Figure 1 that follows shows the fertility rates in urban and rural areas of Russia marking its strong dependency on rural-urban migration without the international inward migration.

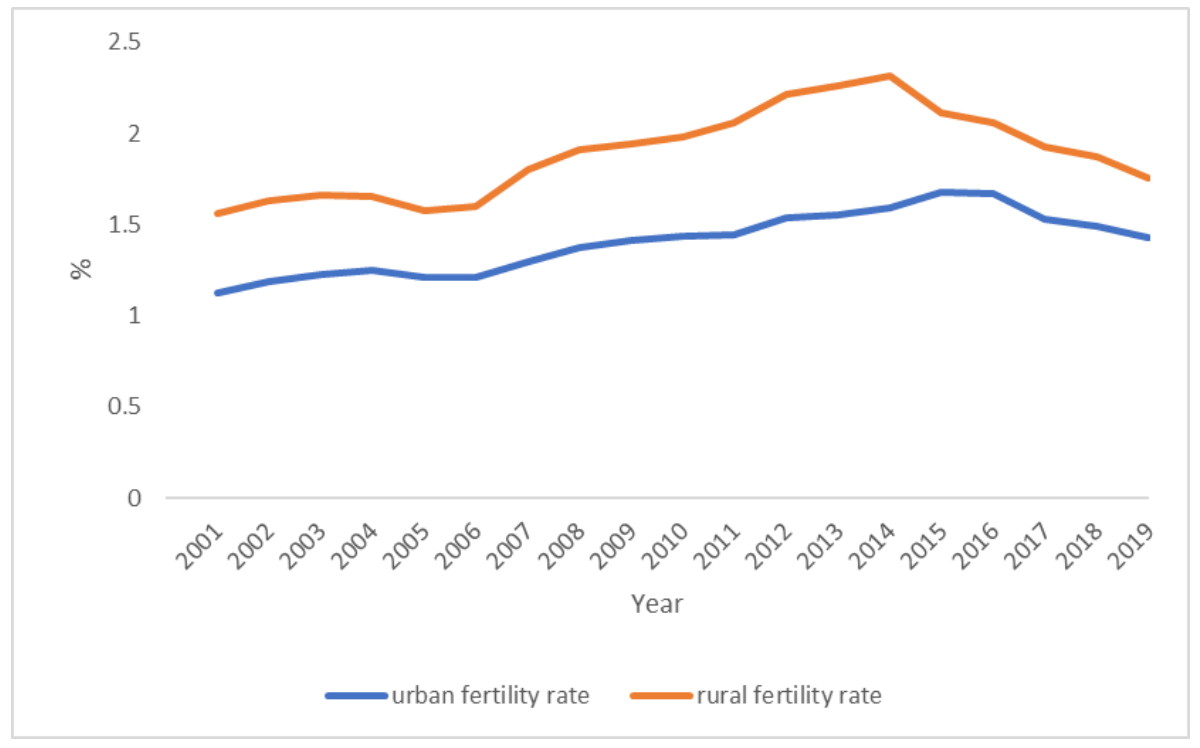

Fig. 1. Fertility rate in the Russian Federation (rural and urban comparison)

The environmental policy in Russia should cover all possible economic benefits arising from natural resources and simply from pollution problems, as well as an integrated approach to environmental management and the protection of human health and safety. The strategy must have strongly emphasised the importance of environmental safety, which must be defined and a high level of attention paid to issues such as water, air, land, soil and water quality. Environmental issues must also be addressed in the context of the affirmation of state sovereignty over natural resources and the protection of human health and safety. In this regard, Russia has often used elements of the environmental security agenda in economic cooperation. Russia is also making significant contributions to the development of cooperation in the fields of environment and security with other countries in the region. It must commit itself strongly to participating in multilateral efforts aimed at reducing the 
environmental impact of its economic activities through technology development projects. Several years ago, the Russian government published a plan to develop a low-carbon economy, making cutting emissions one of its top priorities for the next five years. But Russian leaders expressed scepticism that the effects of climate change can actually be good for Russia. The Russian government is already planning to take advantage of climate change to use the resources and additional land available from the melting of sea ice. For example, the Arctic melting can be used as part of its long-term security strategy for the future [23].

\section{Conclusions and policy implications}

When considering the results of this elaboration, we advocate the importance of environmental sustainability in developing countries as an emerging urban environmental challenge. Accordingly, it has attracted the attention of many scientists as a possible solution to the problem of climate change and its impact on human health and the environment. With an increasing urban population, the quality of the urban environment is playing an increasingly important role in the field of public health, with issues ranging from the interface between urban poverty and the environment to health. There are therefore a number of interrelated urban environmental and health threats to which urban residents in developing countries are exposed. This makes developing cities an emerging environment for health and environmental sustainability, as well as for economic development. With an increasing urban population, the quality of the urban environment is playing an increasingly important role in public health, with issues ranging from the interface between urban poverty and the environment to health. There are a number of significant interrelated environmental and health risks to which urban dwellers in developing countries are exposed.

Moreover, the links between health and the environment are inadequate in a number of policy areas and are therefore often overlooked in policy. Cities and municipalities are increasingly working to reduce many of these problems through best practices, outreach and education. Urban areas can promote green buildings to reduce the risk of air pollution, water pollution and air quality problems. Growth can be contained in a way that protects the habitat of rural areas and preserves human and environmental health in urban areas, as well as the biodiversity of the natural environment. The role of green infrastructure in urban management in the development of sustainable urban planning is also important. Partners can work together to develop a "green infrastructure" for urban areas, which is a networked network of protected natural spaces with protected features designed to support native species, preserve natural ecological processes and contribute to the health and quality of life of the community.

One can see that since the 1980 s, the idea of the relationship between the city and the environment has changed dramatically. This understanding has become widely accepted among those involved in the management of cities around the world. It is accepted that environment and development go hand in hand in the development of sustainable urban planning, and this understanding is increasingly being shared among urban planners, and policymakers. Then we can argue that urban and environmental issues are multiple issues and that they are inextricably linked and form the basis for future strategies on urban development, urban sustainability and urban environmental management. Practices that are now taken for granted, such as urban planning for cars, single-family housing and urban planning, will no longer be economically, environmentally or culturally sustainable. A new understanding of what constitutes good urban planning and design is needed to effectively meet the needs of the urban environment, as well as the health and well-being of citizens and the environment. To address these changes in urban planning and planning, we present the following principles. Given the associated urban sprawl in developed areas, the debate is about the optimal spatial configuration on which urban planning should be based. The focus 
of this debate is on the development of a so-called compact city, with a mix of single-family, mixed-use and multi-family buildings. In recent years, a model has been developed that borrows from the United Nations Sustainable Development Goals (SDGs). Sustainable Cities goal 4 was introduced as a means of investigating the impact of urbanization on environmental integrity. It is true, for example, that increased urban development is largely linked to greater human well-being - being. Resolving such tensions and educating people on how sustainable cities can promote human health, the environment and human well-being while being sustainable are key to achieving Sustainable City Goal 11 and are addressed in several other Sustainable Development Goals.

There are many studies based on post-industrial cities could, however, provide insights that could help newly developed nations such as the Unite States and China better understand the social and environmental challenges of urbanization. These findings, and the associated notions of environmental sustainability, could provide an opportunity for environmentalists and planning authorities engaged in sustainable urbanization to deepen their understanding of the impact of urbanization on environmental integrity. This is particularly true in global megacities, where the environmental impacts of urbanization, such as air and water pollution, water quality and climate change, can be significantly higher than in rural areas. This challenge underlines the need for integrated assessment methods that take into account the complex interactions, including the impact of the urban environment on the health and sustainability of its inhabitants. Various metrics can be presented to understand how urban forms and their related environmental and social impacts, as well as the impacts of human activities, can influence the resilience of increased urban warming. All of the above might mean some valuable lessons for the environmental security and urban development in countries like the Russian Federation.

\section{References}

1. F. Dell'Anna, Energy Policy, 149, 112031 (2021)

2. R. Kumar, Strategic Analysis, 44(5), 479-489 (2020)

3. S. Formankova, O. Trenz, O. Faldik, J. Kolomaznik, P. Vanek, Marketing and Management of Innovations, 2, 94-102 (2018)

4. W. Strielkowski, Social Impacts of Smart Grids: The Future of Smart Grids and Energy Market Design (2019)

5. T. Ide, C. Bruch, A. Carius, K. Conca, G. Dabelko, R. Matthew, E. Weinthal, International Affairs, 97(1), 1-16 (2021)

6. S. Sellers, K. Ebi, J. Hess, Environmental Health Perspectives, 127(04), 045002 (2019)

7. R. Prăvălie, G. Bandoc, Journal of Environmental Management, 209, 81-92 (2018)

8. J. Mensah, S. Casadevall, Cogent Social Sciences, 5(1), 1653531 (2019)

9. N. Megahed, E. Ghoneim, Sustainable Cities and Society, 61, 102350 (2020)

10. S. Vegera, A. Malei, R. Trubovich, Entrepreneurship and Sustainability Issues, 6(1), 211-225 (2018)

11. T. Kuramochi, M. Roelfsema, A. Hsu, S. Lui, A. Weinfurter, S. Chan, A. Clapper, A. Chang, N. Höhne, Climate Policy, 20(3), 275-291 (2020)

12. D. López-Carr, J. Burgdorfer, Environment: Science and Policy for Sustainable Development, 55(1), 3-11 (2013)

13. P. Sandifer, A. Sutton-Grier, B. Ward, Ecosystem Services, 12, 1-15 (2015)

14. P. Smith, J. House, M. Bustamante, J. Sobocká, R. Harper, G. Pan, P. West, J. Clark, T. Adhya, C. Rumpel, K. Paustian, P. Kuikman, F. Cotrufo, J. Elliott, R. McDowell, R. Griffiths, S.Asakawa, A. Bondeau, A.Jain, J. Meersmans. T. Pugh, Global Change Biology, 22(3), 1008-1028 (2016) 
15. A. Mah, D. Chapman, E. Markowitz, B. Lickel, Journal of Anxiety Disorders, 75, $102282(2020)$

16. D. Dushkova, D. Haase, Land, 9(1), 19 (2020)

17. W. Strielkowski, T. Veinbender, M. Tvaronavičienė, N. Lace, Economic ResearchEkonomska Istraživanja, 33(1), 788-803 (2020)

18. A. Revi, I. Anguelovski, W. Leal Filho, M. Olazabal, E. Chu, J. Cooper, M. Garschagen, D. Nelson, One Earth, 3(4), 384-387 (2020)

19. R. Avtar, S. Tripathi, A. Aggarwal, P. Kumar, Resources, 8(3), 136 (2019)

20. S. Kulik, E. Travkina, A. Fedorov, A. Rubtsova, IOP Conference Series: Earth and Environmental Science, 302(1), 012011 (2019)

21. Z. Chen, H. Yin, International Affairs, 96(3), 787-805 (2020)

22. T. Mitrova, Y. Melnikov, Energy Transitions, 3(1), 73-80 (2019)

23. S. Stephenson, R. Pincus, Journal of Borderlands Studies, 33(2), 255-27 (2018) 